\title{
Effects of Patient-Pharmacist Communication on the Treatment of Asthma
}

\author{
Mitsuko Onda, ${ }^{*, a}$ Hidehiko SakURaI, ${ }^{b}$ Yukitoshi Hayase, ${ }^{b}$ Hiroyuki SaKamaki, ${ }^{c}$ \\ Yukio ARAKAWA, ${ }^{a}$ and Fumiaki YASUKAWA ${ }^{d}$ \\ aOsaka University of Pharmaceutical Sciences, 4-20-1 Nasahara, Takatsuki, Osaka 569-1094, Japan, \\ ${ }^{b}$ Hokkaido Pharmaceutical University, 7-1 Katsuraoka-cho, Otaru 047-0264, Hokkaido, Japan, \\ cFaculty of Pharmaceutical Sciences, Meijo University, 150 Yagotoyama, Tempaku-ku, \\ Nagoya 468-8503, Japan, and ${ }^{d}$ Faculty of Law, Kumamoto University, 39-1, \\ Kurokami 2-chome, Kumamoto 860-8555, Japan
}

(Received June 9, 2008; Accepted December 9, 2008)

\begin{abstract}
We studied the relationship between patient-pharmacist communication and asthma treatment, including patient understanding of drug therapy, ability to self-treat with inhaled drugs, and control over asthma. The study was among adult patients who had received inhaled steroidal or other drugs from community pharmacies in Hokkaido, Ibaragi, Tochigi, Kanagawa, and Osaka prefectures for at least one year. During the month of November 2007, pharmacists explained the study to patients and obtain consent before distributing questionnaires to be filled out and mailed back. Survey items covered the nature/extent of the pharmacist's explanation, the patient's degree of understanding, frequency of inhaled steroid use, frequency of asthma attacks, degree of improvement with inhaler use, skill in using inhaled drugs, and self-evaluation of communication with the pharmacist. Analysis was carried out using the 114 valid data sets obtained. The ratio of men to women was $4: 6$, and the average age was 61.8 years. Compared with patients citing communication problems with pharmacists, those who had good communication received significantly higher scores in terms of understanding the purpose of inhalers, drug interactions, and side effects, and coping with attacks, as well as in indices of skill in using inhaled drugs. The degree of improvement in asthma attacks was also significantly higher among patients with self-evaluation of good communication with pharmacists. We suggest that communication between patient and pharmacist is associated with understanding of pharmacotherapy, as well as their ability to use inhaled medications and gaining good control over their asthma.
\end{abstract}

Key words_asthma; pharmacist; communication; outcome; pharmacy

\section{INTRODUCTION}

Bronchial asthma has come to be regarded as a "chronic inflammation of the respiratory tract," and Japan's set of guidelines for the prevention and management of asthma, the Global Initiative for Asthma, cites inhaled steroidal medications with excellent anti-inflammatory effects as the drugs of choice for use in the long-term management of asthma. ${ }^{1)}$ However, for the effects of inhaled steroids to be fully felt, it is essential that the patient learns the proper inhalation technique and uses the medications continuously according to the instructions given by the medical provider.

In the treatment of asthma, it is desirable that medical providers work as a team with the patient, checking the patient's inspiratory flow rate and then guiding the patient in the proper method for inhaling steroids after first providing a thorough explanation

*e-mail: onda@gly.oups.ac.jp of the nature of asthma, purpose of pharmacotherapy, necessity for continuous management, characteristics and timing of the use of various inhaled drugs, side effects, drug interactions, etc. However, physicians sometimes indicate that they do not have time to provide careful inhalation guidance to patients, and fearing that patient compliance will be poor, they avoid prescribing inhaled steroids to asthma patients. ${ }^{2)}$ Moreover, it has been reported that the rate of the use of inhaled steroids among Japanese adults is low at $12 \%$, and even when they are prescribed, there are problems with ensuring compliance, for such reasons as the patient "does not understand how to use inhalation drugs" or finds using them "a troublesome." Researchers have pointed to the necessity of consistent patient guidance with good coordination between the efforts of physicians and pharmacists as the best way of coping with these problems. ${ }^{3)}$

There have been several prior reports on research assessing the intervention of pharmacists in the treat- 
ment of asthma patients. The effects of such intervention in the form of providing explanations of inhaled steroids, inhalation guidance, and patient counseling have been verified using such evaluation indices as asthma patients' knowledge of medications and degree of compliance, the effects of treatment (improvement in peak flow values, etc.), improvement in quality of life, frequency of the use of fast-acting inhaled $\beta_{2}$ stimulants, patient degree of satisfaction, and whether or not emergency hospitalization was needed. In cases studied within Japan, the effects of intervention on the part of the pharmacist were generally good, ${ }^{2,4-8)}$ and improved compliance was thought to be backed by an improvement in pharmacists' ability to provide guidance (such as listening to the patient's comments first before beginning to provide guidance instead of offering a unilateral explanation) .2) In cases studied overseas, on the other hand, variations in evaluations of the effectiveness and usefulness of intervention were observed, depending upon the caliber and degree of experience of the pharmacist, the nature of the intervention, and how proactive the pharmacist was in providing guidance, etc. ${ }^{9-12)}$ There have, however, been no prior examples of verification studies focusing on communication between patient and pharmacist, either in Japan or elsewhere.

This study aimed to examine the association that communication between patient and pharmacist had with the patient's degree of understanding of pharmacotherapy, skill in using inhaled drugs, and success in controlling asthma, etc.

\section{METHODS}

Pharmacists at participating pharmacies in Hokkaido, Tochigi, Ibaragi, Kanagawa, Chiba, Saitama, Tokyo, and Osaka prefectures were asked to select patients to be surveyed. Study patients had to meet two selection criteria: 1) be adult asthma patients who had received inhaled steroidal medications, along with guidance in their use, for the past year or more at the participating pharmacy; and 2) be patients visiting or scheduled to visit the pharmacy within the study period (early November through the end of November). No upper limit was set on the number of patients selected, but the number naturally fell within the scope of willing participants. Then the pharmacists distributed questionnaire forms to be filled out by patients themselves.
Eligible patients visiting the pharmacy received an explanation of the purpose of the survey and were asked to participate. Patients from whom consent was obtained were given a "Patient Questionnaire Form" and a return envelope from the supply provided to the participating pharmacy in advance, and the patients were asked to fill out the questionnaires and mail them back, not to the pharmacy, but directly to the principal investigator.

The questionnaires were devised with reference to asthma treatment guidelines, consultations among researchers, results of previous research reviews, and items in the Asthma Control Test (ACT) . ${ }^{13)}$ Prior to carrying out the study, we sought the opinions of physicians specializing in respiratory organ diseases and pharmacists working at hospitals or pharmacies. We repeatedly refined the questionnaire so as to most efficiently collect information that would be meaningful clinically, while taking into account the burden on patients in responding to the questionnaire. The main survey items were as follows: 1) gender, 2) age, 3) frequency of asthma attacks over the course of the past month and frequency of use of fast-acting inhaled $\beta_{2}$ stimulants (relievers), 4) degree of control over asthma during most recent 1-month period (selfevaluation), 5) degree of improvement in extent and frequency of asthma attacks from the time the patient began using inhaled steroids, 6) degree of understanding of the pharmacist's inhalation guidance, 7) ability to use inhaled steroids skillfully (self-evaluation), and 8) state of communication with the pharmacist (self-evaluation).

Results obtained for items 3)-7) were successively compared in terms of the quality of communication. For statistical analysis, we used Windows SPSS (12.0J). The Mann-Whitney test (U-test) was performed to assess significant differences in patient distribution (5\% was adopted as the significance standard). The question items and the classifications of patient groups used at the time of performing the Utest are shown in Table 1. In deciding upon the classifications for patient groups, we took into consideration the goals of the study and the distributional balance among groups of patients.

\section{RESULTS}

We requested 178 patients to respond to the research questionnaire. Six patients refused to comply. As a result, we collected 121 responses for 172 distri- 
Table 1. Question Items and Scores

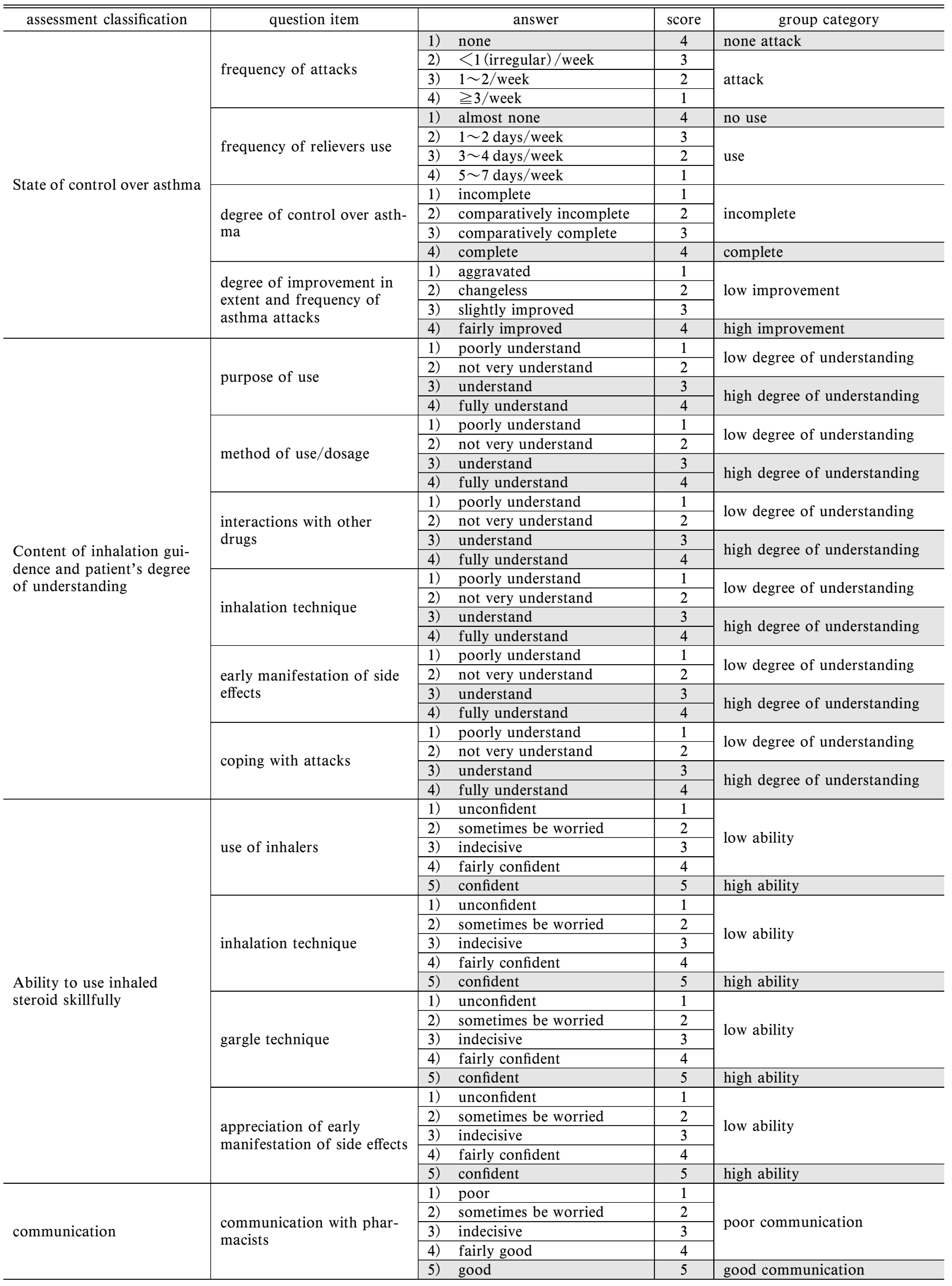


butions (recovery rate: $70.3 \%$ ). For analysis, we used the data for the 114 cases in which we were able to obtain valid responses (practical recovery rate: $66.3 \%$ ). In terms of gender, the group consisted of 45 men $(39.5 \%), 68$ women $(59.6 \%)$, and one unknown $(0.9 \%)$. The average age was 61.8 years, with $11.4 \%$ less than 40 years of age, $21.1 \% 40$ to 59 years of age, and $66.6 \% 60$ years of age or older, and 1 unknown $(0.9 \%)$.

\section{Investigation Using U-test}

(1) Association between self-evaluation of patientpharmacist communication and control over asthma

We compared the patient distributions for the good communication group and poor communication group with respect to the assessment classifications for "state of control over asthma" (4 items in Table 1). A significant difference was found for degree of improvement in asthma attacks following the use of inhaled steroids, with the percentage of patients in the high improvement group significantly higher for the good communication group than for the poor communication group (Table 2) .

(2) Association between self-evaluation of patientpharmacist communication and patient's degree of understanding of inhalation guidance

We compared the patient distributions for the good communication group and poor communication group with respect to the assessment classifications for "content of guidance and degree of patient understanding" (6 items in Table 1). Significant differences were found for the purpose of use, interactions with other drugs, early manifestation of side effects, and

Table 2. Relationship between Quality of Patient-Pharmacist Communication and Control over Asthma

\begin{tabular}{|c|c|c|c|c|}
\hline \multirow{2}{*}{ question item } & \multirow{2}{*}{ group category } & \multicolumn{2}{|c|}{$\underset{(\%)}{\operatorname{communication}}$} & \multirow{2}{*}{$p$} \\
\hline & & good & poor & \\
\hline \multirow{2}{*}{$\begin{array}{l}\text { frequency of } \\
\text { attacks }\end{array}$} & none attack & 52.3 & 43.9 & \multirow{2}{*}{0.393} \\
\hline & attack & 47.7 & 56.1 & \\
\hline \multirow{2}{*}{$\begin{array}{l}\text { frequency of } \\
\text { relievers use }\end{array}$} & no use & 58.1 & 60.3 & \multirow{2}{*}{0.823} \\
\hline & use & 41.9 & 39.7 & \\
\hline \multirow{2}{*}{$\begin{array}{l}\text { degree of control } \\
\text { over asthma }\end{array}$} & complete & 39.5 & 25.0 & \multirow{2}{*}{0.112} \\
\hline & incomplete & 60.5 & 75.0 & \\
\hline \multirow{2}{*}{$\begin{array}{l}\text { degree of improve- } \\
\text { ment in extent and } \\
\text { frequency of asth- } \\
\text { ma attacks }\end{array}$} & high improvement & 70.5 & 45.5 & \multirow{2}{*}{0.011} \\
\hline & low improvement & 29.5 & 54.5 & \\
\hline
\end{tabular}

coping with asthma attacks, with the percentage of patients in the high degree of understanding group significantly higher for the good communication group than for the poor communication group (Table $3)$.

(3) Association between self-evaluation of patientpharmacist communication and ability to use inhaled steroids skillfully

We compared the patient distributions for the good communication group and poor communication group with respect to the assessment classifications for "ability to use inhaled steroids skillfully" (4 items in Table 1). Significant differences were found for all 4 items, with the percentage of patients in the high ability group significantly higher for the good communication group than for the poor communication group (Table 4) .

(4) Relationship between degree of understanding of inhalation guidance and control over asthma

Table 3. Relationship between Quality of Patient-Pharmacist Communication and Patient's Degree of Understanding of Inhalation Guidance

\begin{tabular}{|c|c|c|c|c|}
\hline \multirow{2}{*}{ question item } & \multirow{2}{*}{ group category } & \multicolumn{2}{|c|}{$\underset{(\%)}{\operatorname{communication}}$} & \multirow{2}{*}{$p$} \\
\hline & & good & poor & \\
\hline \multirow{2}{*}{ purpose of use } & $\begin{array}{l}\text { low degree of } \\
\text { understanding }\end{array}$ & 0.0 & 11.9 & \multirow{2}{*}{0.019} \\
\hline & $\begin{array}{l}\text { high degree of } \\
\text { understanding }\end{array}$ & 100.0 & 88.1 & \\
\hline \multirow{2}{*}{$\begin{array}{l}\text { method of use/ } \\
\text { dosage }\end{array}$} & $\begin{array}{l}\text { low degree of } \\
\text { understanding }\end{array}$ & 0.0 & 4.5 & \multirow{2}{*}{0.153} \\
\hline & $\begin{array}{l}\text { high degree of } \\
\text { understanding }\end{array}$ & 100.0 & 95.5 & \\
\hline \multirow{2}{*}{$\begin{array}{l}\text { interactions with } \\
\text { other drugs }\end{array}$} & $\begin{array}{l}\text { low degree of } \\
\text { understanding }\end{array}$ & 11.4 & 50.8 & \multirow{2}{*}{$<0.001$} \\
\hline & $\begin{array}{l}\text { high degree of } \\
\text { understanding }\end{array}$ & 88.6 & 49.2 & \\
\hline \multirow{2}{*}{ inhalation technique } & $\begin{array}{l}\text { low degree of } \\
\text { understanding }\end{array}$ & 0.0 & 4.5 & \multirow{2}{*}{0.157} \\
\hline & $\begin{array}{l}\text { high degree of } \\
\text { understanding }\end{array}$ & 100.0 & 95.5 & \\
\hline \multirow{2}{*}{$\begin{array}{l}\text { early manifestation } \\
\text { of side effects }\end{array}$} & $\begin{array}{l}\text { low degree of } \\
\text { understanding }\end{array}$ & 13.6 & 51.5 & \multirow{2}{*}{$<0.001$} \\
\hline & $\begin{array}{l}\text { high degree of } \\
\text { understanding }\end{array}$ & 86.4 & 48.5 & \\
\hline \multirow{2}{*}{ coping with attacks } & $\begin{array}{l}\text { low degree of } \\
\text { understanding }\end{array}$ & 6.8 & 32.3 & \multirow{2}{*}{0.002} \\
\hline & $\begin{array}{l}\text { high degree of } \\
\text { understanding }\end{array}$ & 93.2 & 67.7 & \\
\hline
\end{tabular}


Table 4. Relationship between Quality of Patient-Pharmacist Communication and Ability to Use Inhaled Steroids Skillfully

\begin{tabular}{|c|c|c|c|c|}
\hline \multirow{2}{*}{ question item } & \multirow{2}{*}{ group category } & \multicolumn{2}{|c|}{$\underset{(\%)}{\text { communication }}$} & \multirow{2}{*}{$p$} \\
\hline & & good & poor & \\
\hline \multirow{2}{*}{ use of inhalers } & low ability & 2.3 & 58.2 & \multirow{8}{*}{$<0.001$} \\
\hline & high ability & 97.7 & 41.8 & \\
\hline \multirow{2}{*}{ inhalation technique } & low ability & 6.8 & 58.2 & \\
\hline & high ability & 93.2 & 41.8 & \\
\hline \multirow{2}{*}{ gargle technique } & low ability & 11.4 & 56.7 & \\
\hline & high ability & 88.6 & 43.2 & \\
\hline \multirow{2}{*}{$\begin{array}{l}\text { appreciation of ear- } \\
\text { ly manifestation of } \\
\text { side effects }\end{array}$} & low ability & 34.9 & 87.3 & \\
\hline & high ability & 65.1 & 12.7 & \\
\hline
\end{tabular}

Table 5. Relationship between Degree of Understanding of Inhalation Guidance and Control over Asthma

\begin{tabular}{|c|c|c|c|c|}
\hline \multirow{2}{*}{$\begin{array}{l}\text { question } \\
\text { item }\end{array}$} & \multirow{2}{*}{ group category } & \multicolumn{2}{|c|}{ degree of improvement ${ }_{(\%)}^{*}$} & \multirow{2}{*}{$p$} \\
\hline & & $\begin{array}{l}\text { high } \\
\text { improvement }\end{array}$ & $\begin{array}{c}\text { low } \\
\text { improvement }\end{array}$ & \\
\hline \multirow{2}{*}{$\begin{array}{l}\text { purpose of } \\
\text { use }\end{array}$} & $\begin{array}{l}\text { low degree of } \\
\text { understanding }\end{array}$ & 1.6 & 18.4 & \multirow{2}{*}{0.002} \\
\hline & $\begin{array}{l}\text { high degree of } \\
\text { understanding }\end{array}$ & 98.4 & 81.6 & \\
\hline \multirow{2}{*}{$\begin{array}{l}\text { method of } \\
\text { use/dosage }\end{array}$} & $\begin{array}{l}\text { low degree of } \\
\text { understanding }\end{array}$ & 0.0 & 8.2 & \multirow{2}{*}{0.022} \\
\hline & $\begin{array}{l}\text { high degree of } \\
\text { understanding }\end{array}$ & 100.0 & 91.9 & \\
\hline \multirow{2}{*}{$\begin{array}{l}\text { interactions } \\
\text { with other } \\
\text { drugs }\end{array}$} & $\begin{array}{l}\text { low degree of } \\
\text { understanding }\end{array}$ & 26.2 & 44.9 & \multirow{2}{*}{0.042} \\
\hline & $\begin{array}{l}\text { high degree of } \\
\text { understanding }\end{array}$ & 73.8 & 55.1 & \\
\hline
\end{tabular}

*: degree of improvement in extent and frequency of asthma attacks from the time the patient began using inhaled steroids.

We analyzed the responses in terms of the assessment classifications for "content of inhalation guidance and degree of patient understanding" and "state of asthma control" in Table 1 . We found that the degree of improvement in asthma attacks derived from using inhaled steroids was high for patients claiming a high degree of understanding of the purpose of use, method of use/dosage, and interactions with other drugs (Table 5).

(5) Relationship between ability to use inhaled steroids skillfully and control over asthma

We analyzed the responses in terms of the assess-
Table 6. Relationship between Ability to Use Inhaled Steroids Skillfully and Control over Asthma

\begin{tabular}{|c|c|c|c|c|}
\hline \multirow{2}{*}{$\begin{array}{l}\text { question } \\
\text { item }\end{array}$} & \multirow{2}{*}{$\begin{array}{l}\text { group } \\
\text { category }\end{array}$} & \multicolumn{2}{|c|}{$\begin{array}{c}\text { degree of control over asthma } \\
(\%)\end{array}$} & \multirow{2}{*}{$p$} \\
\hline & & complete & incomplete & \\
\hline \multirow{2}{*}{$\begin{array}{l}\text { use of } \\
\text { inhalers }\end{array}$} & low ability & 20.6 & 43.4 & \multirow{2}{*}{0.022} \\
\hline & high ability & 79.4 & 56.6 & \\
\hline \multirow{2}{*}{$\begin{array}{l}\text { inhalation } \\
\text { technique }\end{array}$} & low ability & 17.6 & 43.4 & \multirow{2}{*}{0.009} \\
\hline & high ability & 82.4 & 56.6 & \\
\hline \multirow{2}{*}{$\begin{array}{l}\text { question } \\
\text { item }\end{array}$} & \multirow{2}{*}{$\begin{array}{l}\text { group } \\
\text { category }\end{array}$} & \multicolumn{2}{|c|}{ degree of improvement*(\%) } & \multirow[b]{2}{*}{$p$} \\
\hline & & $\begin{array}{l}\text { high } \\
\text { improvement }\end{array}$ & $\begin{array}{l}\text { low } \\
\text { improvement }\end{array}$ & \\
\hline \multirow{2}{*}{$\begin{array}{l}\text { inhalation } \\
\text { technique }\end{array}$} & low ability & 25.4 & 48.0 & \multirow{2}{*}{0.01} \\
\hline & high ability & 74.6 & 52.0 & \\
\hline
\end{tabular}

*: degree of improvement in extent and frequency of asthma attacks from the time the patient began using inhaled steroids.

ment classifications for "ability to use inhaled steroids skillfully" and "state of asthma control" in Table 1 . We found that the patients who were highly skilled in using inhalers had a greater sense of control over their asthma, while patients who were skilled in inhalation techniques had higher scores for both sense of control over their asthma and degree of improvement in asthma attacks due to inhaled steroid use (Table 6).

\section{DISCUSSION}

Because we relied upon pharmacists at participating pharmacies to select the patients, selection bias occurred in this study. However, considering 1) the fact that uniform selection criteria for use in selecting patients were made clear in advance, 2) we adopted a method whereby the completed questionnaires were not collected by the pharmacists but returned directly to the principal investigator, and 3) the age distribution of the patients, we found that almost all agegroups were covered and there was no extreme bias, judging from the research aims of this study and the attributes of patients. For these reasons, we made the judgment that any existing bias would not seriously affect the results of this study.

In the U-test assessment, we found a tendency for good communication to influence more concrete question items, such as "degree of improvement in asthma attacks following use of inhaled steroids" as an aspect of asthma control, as well as understanding of the "purpose of use," "interactions with other 
drugs," "early manifestation of side effects," and "coping with attacks" as aspects of the patient's degree of understanding, and all of the question items under the rubric of "ability to use inhaled steroids skillfully." These results indicate that the communication between patient and pharmacist has an influence upon the patient's degree of understanding of inhalation guidance and skill in using inhaled steroidal drugs.

At the same time, our investigation of the relationship between asthma control and question items pertaining to the degree of understanding of inhalation guidance and ability to use inhaled steroids skillfully showed that the patient's degree of understanding (especially with respect to the purpose of use, method of use/dosage, and interactions with other drugs for inhaled steroids), together with the ability to use inhaled steroids skillfully (in particular, use of inhalers and inhalation technique) exerted an affect upon the patient's sense of control over asthma and the degree of improvement in asthma attacks. As one explanation, this suggests that by enhancing the patient's degree of understanding and skill in using treatment methods involving inhaled steroids, good communication between patient and pharmacist positively influences the overall outcome of asthma treatment. However, the result may possibly be interpreted as showing that the patients' self-evaluation of communication with pharmacist in the high improvement group was higher than that of patients in the low improvement group from the outset. Therefore, the matter needs further study to verify the validity of the implications of this investigation.

\section{CONCLUSIONS}

The results of our study imply that communication between patient and pharmacist was associated with patient understanding of pharmacotherapy as well as their ability to use inhaled medications and to gain good control over their asthma. Pharmacists working in pharmacies are in a position to intervene effectively in the treatment of asthma for outpatients. However, what tends to develop is a situation wherein the pharmacist provides a one-sided, standardized explanation, without taking into account the patient's degree of understanding or background. In many cases, the pharmacist fails to listen adequately to the patient's problems and neglects to instruct the patient in inhalation technique or to confirm compliance. In the fu- ture, it will be necessary to make a more concrete study of the factors necessary to improve pharmacists' communication with patients. At the same time, research must be conducted on methods for promoting more effective, efficient communication in the midst of a busy and complex work environment.

Acknowledgments We would like to express our deep gratitude to the pharmacists, patients, and others who participated in this study. This paper is based in part on research funded by Doshisha University's Institute for Technology, Enterprise Competitiveness 21st Century Centre of Excellence Program (Synthetic Studies on Technology, Enterprise and Competitiveness), including the subproject entitled "Relationship between the fruits of progress in medical technology and the allocation of human resources," sponsored by the Ministry of Education, Culture, Sports, Science and Technology of Japan.

\section{REFERENCES}

1) National Institutes of Health, National Heart, Lung, and Blood Institutes: Global strategy for asthma management and prevention. NHLBI/WHO Workshop Report, revised, 1172 (2002).

2) Inoue T., Kurohoshi M., Sato M., Toyama T., Tsukui T., Ogame Y., Tokumatsu E., Igaku to Yakugaku, 54, 839-847 (2005).

3) Horiguti T., Ohira D., Hayashi N., Kobayashi K., Torigoe H., Ito T., Hirose M., Sasaki Y., Shiga M., Miyazaki J., Kondo R., Tachikawa S., Uno H., Nakano I., Nippon Kyobu Rinsho, 65, 562-568 (2006).

4) Watanabe T., Sawai N., Ohta M., Tanaka Y., Murata M., Yamamoto T., Jpn. J. Pharm. Health Care Sci., 29, 83-91 (2003).

5) Onda M., Kobayashi S., Kuroda K, Zenda H., Hospital Administration 41, 255-262 (2004).

6) Takagi M., Miyashita Y., Kameda M., Miyashita Y., Kameda M., Doi S., Toyoshima K., Yunoki S., Jpn. J. Pediatric Society of Intractable Asthma and Allergic Diseases, 3, 180 -184 (2005).

7) Misaki Y., Kanda K., Jpn. J. Hospital Pharmacist, 40, 1408-1410 (2004).

8) Yamaoka K., Iguchi E., Kubota S., Allergy, 51, 1170-1176 (2002).

9) Cordina M., McElnay J., Hughes C., Phar- 
macotherapy, 21, 196-1203 (2001).

10) Weinberger M., Murray M., Marrero D., Brewer N., Lykens M., Harris E., Seshadri R., Caffrey H., Roesner F., Smith F., Newell J., Collins C., McDonald J., Tierney M., JAMA, 288, 1594-1602 (2002).

11) Stergachis A., Gardner J., Anderson M., Gardner S., Anderson T., Sullivan D., Journal of the American Pharmaceutical Association, 42, 743-752 (2002).

12) McLean W., Gillis J., Waller R., Can. Respir. J., 10, 195-202 (2003).

13) Schatz M., Sorkness A., Li T., Marcus P., Murray J., Nathan A., Kosinski M., Pendergraft B., Jhingran P., J. Allergy Clin. Immunol., 117, 549-556 (2006). 